\title{
Portal Veins of Mice Infected with Schistosoma mansoni Exhibit an Increased Reactivity to 5-Hydroxytryptamine
}

\author{
CLM Silva, N Morel, F Noël/ ${ }^{+}$ \\ Departamento de Farmacologia Básica e Clínica, ICB, Universidade Federal do Rio de Janeiro, Cidade \\ Universitária, 21941-590 Rio de Janeiro, RJ, Brasil
}

In chronic severe infection with Schistosoma mansoni, portal hypertension and related vascular alterations usually develop as a consequence of granulomatous response to eggs. In order to investigate a putative direct effect of worms on the reactivity of their host portal vein, mice infected only with male worms were used in the present study. An higher reactivity to 5-hydroxytryptamine (5-HT) characterized by an increase in the maximal contraction and sensitivity was observed in portal vein from infected mice compared to healthy mice. Blockade of NO-synthase with l-NAME induced a small increase in 5-HT potency in portal vein from non-infected mice without changing the amplitude of the contractions, whereas it did not alter the reactivity of veins from infected mice. The present results show that unisexual infection of mice with male S. mansoni increased the reactivity of the portal vein to 5-HT which seems to be partially related to an alteration in the nitric oxide release by endothelium.

Key words: portal vein - Schistosoma mansoni - endothelium - 5-hydroxytryptamine

Schistosoma mansoni is mainly located in the mesenteric vessels where the female worms lay hundreds of eggs daily during years (Webbe 1981), leading to a granulomatous response. The anatomical and physiological changes that occur in the portal vasculature during a chronic severe infection accompany the portal hypertension as a consequence of the periportal fibrosis (Bosch et al. 1992, File 1995, Moreno et al. 1996). Since the male worm can fix to the endothelium via its ventral sucker, a direct effect (that means independent of an inflammatory response to eggs) on vein endothelium could also be responsible for an alteration of vascular reactivity. To investigate this possibility we used mice infected unisexually with male worms for studying the contractile response of portal vein to 5-hydroxytryptamine (5-HT), an endogenous agonist that is already known to be involved in the maintenance of mesenteric venous

This work was supported by CAPES, FAPERJ and FINEP (PRONEX no. 41.96.0888.00), Brazil.

CLM Silva is a fellow of CAPES (Brazil). N Morel was supported by grant of CNPq (Brazil)/FNRS (Belgium) and on leave from Laboratoire de Pharmacologie, Université Catholique de Louvain, FARL 5410, Avenue Hippocrate 54, B-1200 Bruxelles, Belgium.

${ }^{+}$Corresponding author. Fax: +55.21.280.4694. E-mail: fnoel@ pharma.ufrj.br

Received 4 May 1998

Accepted 31 August 1998 tone. A possible alteration of the endothelial 1arginine/nitric oxide pathway (Moncada et al. 1991, Salomone et al. 1996) was also investigated.

\section{MATERIALS AND METHODS}

Infection of mice - Male cercariae of S. mansoni (BH strain) were obtained from snails (Biomphalaria glabrata) previously infected with a single male miracidium. Newborn Swiss white mice (3-5 days) were then infected percutaneously with approximately 150 cercariae.

In vitro experiment -The animals were anesthetized with ether and killed by cervical dislocation about 75 days after the infection. The portal vein was carefully removed, freed of connective tissue and worms removed from the veins by flushing physiological solution in the lumen. The same treatment was applied to the veins isolated from non-infected mice. About $5 \mathrm{~mm}$ of tissue was set up longitudinally in a bath filled with physiological solution $\left(\mathrm{NaCl} 122 \mathrm{mM}, \mathrm{KCl} 5 \mathrm{mM}, \mathrm{NaHCO}_{3}\right.$ $15 \mathrm{mM}$, glucose $11.5 \mathrm{mM}, \mathrm{MgCl}_{2} 1.2 \mathrm{mM}, \mathrm{CaCl}_{2}$ $1.25 \mathrm{mM}$ and $\mathrm{KH}_{2} \mathrm{PO}_{4} 1.2 \mathrm{mM}$ ) bubbled with a mixture of $95 \% \mathrm{O}_{2}$ and $5 \% \mathrm{CO}_{2}$ at $37^{\circ} \mathrm{C}$. The tension generated was recorded using an isometric transducer connected to a data acquisition system and further quantitated by integration of the tension-time curve over a period of 1-3 min. The integrated tension (expressed in $\mathrm{mN} . \mathrm{s}$ ) was corrected to represent the mean integrated tension for a period of $1 \mathrm{sec}$. The drug-induced tension referred to the difference in the integrated contractile activity measured immediately before and during the application of the drug. The tissue was equilibrated 
under an initial resting tension of $0.5 \mathrm{~g}$ for $60 \mathrm{~min}$ before the addition of cumulative concentrations of 5-HT $\left(10^{-8}-10^{-5} \mathrm{M}\right)$. After washing and recovery for $30 \mathrm{~min}, 100 \mathrm{mM} \mathrm{N}{ }^{\mathrm{W}}$-Nitro-l-Arginine Methyl Ester (1-NAME) was added for 30 min before repeating the concentration-response curve to 5HT.

Statistics $-\mathrm{EC}_{50}$ and $\mathrm{E}_{\max }$ were estimated independently for each experiment by non-linear regression using the simplest model of drug-receptor interaction (Finet et al. 1983). Student's $t$ test for determining the significance of the differences between control and infected groups was performed considering the arithmetic $\left(\mathrm{E}_{\max }\right)$ or geometric $\left(\mathrm{EC}_{50}\right)$ means. A paired $t$-test was used in order to analyze the effect of 1-NAME treatment on $\mathrm{EC}_{50}$ values.

Drugs - 5-hydroxytryptamine hydrochloride (5HT) and $\mathrm{N}^{\mathrm{w}}$-nitro-1-arginine methyl ester (1NAME) were purchased from SIGMA Chemical Co., USA.

\section{RESULTS}

In portal vein from non-infected mice, $10^{-5} \mathrm{M}$ 5-HT induced an increase in the frequency of the rhythmic contractions resulting in an increase in the integrated contractile activity (data not shown). In contrast, in portal vein from infected mice, 5HT produced a tonic increase in tension. The estimated maximal contraction elicited by 5-HT was 2.3-fold higher and the estimated concentration of the agonist producing $50 \%$ of the maximum contraction was slightly lowered in the infected mice compared to the controls (Fig. Table). In order to investigate if the greater contraction of portal vein from the infected mice could be due to an alteration of the l-arginine-NO pathway, we tested the effect of 1-NAME, an inhibitor of nitric oxide synthase, on the responses to 5-HT. In the control group, the pre-incubation with 1-NAME produced a small but significant shift of the concentrationeffect curve to the left, resulting in a 1.7 -fold diminution of the $\mathrm{EC}_{50}$ value for 5-HT, but no change in the amplitude of the maximum contractile response. In contrast, the inhibition of NO-synthase did not alter the response of portal veins from infected mice to 5-HT.

\section{DISCUSSION}

We reported here alterations of portal vein reactivity that occur in an original model of experimental schistosomiasis characterized by the absence of female worms and hence the granulomatous reaction due to the presence of eggs, that is usually considered to be the main cause for the alterations observed in mixed (natural) infections

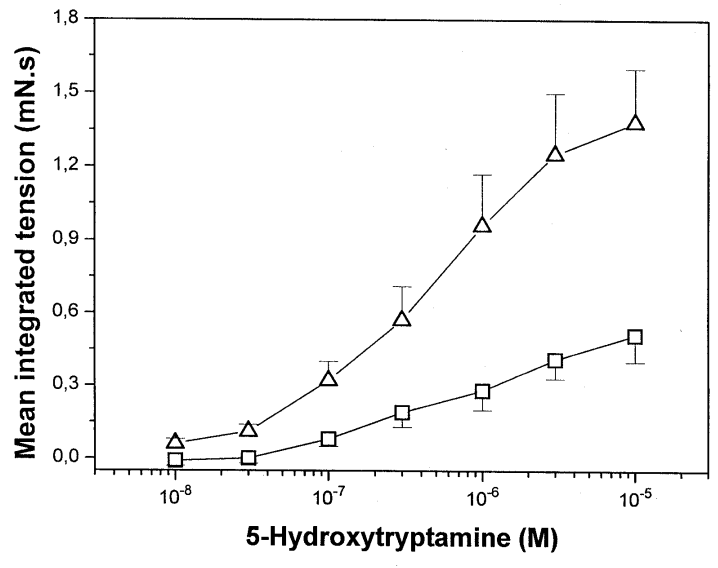

Experimental concentration-response curves to 5-HT of portal veins from mice infected $(\triangle)$ or not $(£)$ with Schistosoma mansoni. Bars represent SEM of 10-11 individual experiments.

TABLE

$\mathrm{EC}_{50}$ and $\mathrm{E}_{\max }$ values for 5-HT induced contractions in portal veins from control and infected mice

\begin{tabular}{ccccc}
\hline \multicolumn{2}{c}{ Control } & & \multicolumn{2}{c}{ Infected } \\
\cline { 1 - 2 } \cline { 4 - 5 } $\begin{array}{c}\mathrm{EC}_{50} \\
(\mathrm{mM})\end{array}$ & $\begin{array}{c}\mathrm{E}_{\max } \\
(\mathrm{mN.s})\end{array}$ & & $\begin{array}{c}\mathrm{EC}_{50} \\
(\mathrm{mM})\end{array}$ & $\begin{array}{c}\mathrm{E}_{\max } \\
(\mathrm{mN} . \mathrm{s})\end{array}$ \\
\hline $\begin{array}{c}0.93 \\
(0.66-1.32)\end{array}$ & $0.60 \pm 0.13$ & $\begin{array}{c}0.40^{a} \\
(0.32-0.51)\end{array}$ & $1.41 \pm 0.27^{b}$ \\
\hline
\end{tabular}

Values represent geometric $\left(\mathrm{EC}_{50}\right)$ or arithmetic $\left(\mathrm{E}_{\max }\right.$ \pm SEM) means of 10-11 experiments (see Materials and methods). Intervals of confidence (for $p £ 0.05$ ) are given in parenthesis.

$a: \mathrm{p} £ 0.05$, Student's $t$ test; $b: \mathrm{p} £ 0.01$, Student's $t$ test.

(Nagy et al. 1981). The principal observation is that portal veins from infected mice displayed an increased reactivity to 5-HT (potency and maximal contraction) when compared to healthy animals. The contractile responses to 5-HT in portal vein from non-infected mice was slightly increased by the blockade of $\mathrm{NO}$ synthesis, in agreement with the effect of $\mathrm{NO}$ on the contractile responses to agonist stimulation in several arteries and veins. Blockade of NO synthase did not affect the contractions evoked by 5-HT in portal vein from infected mice, suggesting that the endothelium could be damaged by the presence of male worms inside the lumen of the vein and/or by their fixation on the vessel wall through their ventral sucker. Such mechanical contact could decrease the endothelium production of NO (Moncada et al. 1991), facilitating the contractile effect of 5-HT. On the other hand the relatively important increase of the maximal 
contraction induced by 5-HT that we observed in infected mice cannot be attributed to a lack in NO release or effect and is more difficult to explain at the moment. It has already been shown that mesenteric veins from rats with different kinds of experimental portal hypertension contracted more to 5-HT than did those from control animals, although there was no difference in the contraction induced by a high $\mathrm{K}^{+}$concentration (Cummings et al. 1986). In the present experiments, an increase in portal pressure due either to the occlusion of intrahepatic veins by worms themselves or to an immunological reaction triggered by male worms cannot be discarded since portal veins from infected mice are clearly dilated as observed during the dissection and as reported in the principal branches of portal vein from cadavers with hepatosplenic shistosomiasis (Andrade \& Cheever 1971). However, the portal hypertension that characterizes the severe chronic form of schistosomiasis is normally expected to occur only in mixed infection where a liver fibrosis caused by an hypersensitivity reaction towards egg antigens occurs.

Concluding, we report here that the portal vein reactivity to 5-HT is greatly increased in mice infected with $S$. mansoni. An important point is that these alterations, partially explained by a worminduced defect in the endothelial production of NO, are independent of the traditional inflammatory response to the presence of eggs. Interestingly, antigens released by adult male worms have been shown to induce cell-cell interactions involving the ICAM-1/LFA-1 (intercellular adhesion molecule1 and lymphocyte function-associated antigen-1 respectively) pathway, resulting in granuloma formation in the absence of eggs (Jacobs et al. 1997), supporting our view of a direct pathological role of the adult male worms. Activation of stretch activated channels (Davies \& Tripathi 1993) could play a role in the increase of maximal contraction of the longitudinal musculature that should result in a higher intensity of the peristaltic movements of the veins. This adaptative change could be interpreted as a tentative to compensate for a putative increase in resistance to blood flow in intrahepatic veins.

\section{ACKNOWLEDGMENTS}

To Dr Lygia dos Reis Corrêa, Instituto Oswaldo Cruz, Rio de Janeiro, Brazil for kindly provided infected mice; to Eliana Freitas do Ó and José Ferreira Oliveira for their skilful technical assistance.

\section{REFERENCES}

Andrade ZA, Cheever AW 1971. Alterations of the intrahepatic vasculature in hepatosplenic schistosomiasis mansoni. Am J Trop Med Hyg 20: 425-432.

Bosch J, Pizcueta P, Feu F, Fernández M, Garcia-Pagán JC 1992. Pathophysiology of portal hypertension. Gastroenterol Clin N Amer 21: 1-14.

Cummings SA, Groszmann RJ, Kaumann AJ 1986. Hypersensitivity of mesenteric veins to 5-hydroxytryptamine- and ketanserine-induced reduction of portal pressure in hypertensive rats. Br J Pharmacol 89: 501-513.

Davies PF, Tripathi SC 1993. Mechanical stress mechanisms and the cell - an endothelial paradigm. Circulation Res 72: 239-245.

File SJ 1995. Interaction of schistosome eggs with vascular endothelium. J Parasitol 81: 234-238.

Finet M, Godfraind T, Noël F 1983. The inotropic effect of ouabain and its antagonism by dihydroouabain in rat isolated atria and ventricles in relation to specific binding sites. Br J Pharmacol 80: 751-759.

Jacobs W, Bogers J, Adriaensen D, Timmerman JP, Deelder A, Van Marck E 1997. In vivo evaluation of adhesion molecule induction and fibrotic potential of Schistosoma mansoni adult worm antigens using confocal laser scanning microscopy. Cell Vision 4: 97-98.

Moncada S, Palmer RM, Higgs EA 1991. Nitric oxide: physiology, pathophysiology and pharmacology. Pharmacol Rev 43: 109-142.

Moreno L, Martinez-Cuesta MA, Piqué JM, Bosch J, Espluges JY 1996. Anatomical differences in responsiveness to vasoconstrictors in the mesenteric veins from normal and portal hypertensive rats. NaunynSchmiedeberg's Arch Pharmacol 354: 474-480.

Nagy BA, File SK, Smith JH 1981. Changes in the enteric vasculature of mice infected with Schistosoma mansoni. Am J Trop Med Hyg 30: 999-1009.

Salomone S, Silva CLM, Morel N, Godfraind, T 1996. Facilitation of the vasorelaxant action of calcium antagonists by basal nitric oxide in depolarized artery. Naunyn-Schmiedeberg's Arch Pharmacol 354: 505-512.

Webbe G 1981. Schistosomiasis: Some advances. $\mathrm{Br}$ Med J 283: 1104- 1109. 
Portal Vein Reactivity to 5-Hydroxytryptamine - CLM Silva et al. 